\title{
Properties of seeds and oil of sunflower of oleinic type of domestic selection
}

\author{
Matveyeva T. ${ }^{1}$, Papchenko V. ${ }^{2}$, Hrigorova L. ${ }^{3}$, Volkotrub S. ${ }^{4}$ \\ Ukrainian research institute of oils and fats of the NAAS, 2A Dziuba Ave., Kharkiv, Ukraine, 61019; e-mail: \\ ${ }^{1}$ matveeva7390@gmail.com, ${ }^{2}$ vikucya@ gmail.com, ${ }^{3}$ lab.fatoil@gmail.com, ${ }^{4}$ office.fatoil@ gmail.com \\ ORCID: ${ }^{10000-0002-3867-8146, ~}{ }^{20000-0002-3692-0699,}{ }^{3} 0000-0003-1137-1176,{ }^{4} 0000-0001-7782-1016$
}

Goal. To study domestic sunflower seeds of line X526B with a high content of oleic acid glycerides and oil obtained from it by the method of one-time pressing. To determine the physical-mechanical properties and quality of seed shearing. To establish the oxidative stability of the oil. Methods. The results of measuring the linear sizes of seeds were processed by methods of mathematical statistics to obtain variation series and distribution curves. The evaluation of the thermooxidative stability of the oil was performed by the method of differential scanning calorimetry. Results. The frequency of X526B sunflower seeds of the same length, width, and thickness is 31,28 , and $40 \%$, respectively, which will have a positive effect on the purification of seed mass from waste and oil impurities before the seeds enter production. The X526B sunflower seed width distribution curve differs slightly from the length and thickness distribution curves because it has several frequency peaks (28 and $23 \%$ ), which can complicate the process of selecting sieves to separate waste. The husk content of this line of sunflower seeds is at the level of $24 \%$, which coincides with the characteristics of classical seeds $(25-30 \%)$. The number of non-grinded seeds decreases with the increasing number of stages of shaking. The period of induction of oxidation of this oil at a temperature of $+110^{\circ} \mathrm{C}$ does not exceed the period of induction of classical sunflower oil and is 321 minutes. Conclusions. The technology of shearing sunflower seeds of the oleinic type is similar to the technology of shearing classic sunflower seeds, namely, the main influence on quantitative and qualitative indicators of shearing is the thickness of the air layer and the strength of the shell. The technological process parameters (seed moisture and rotation of the seed rotor) are secondary. The oil obtained from X526B sunflower seeds is more resistant to oxidation than the classic one, and can therefore be used for cooking at higher temperatures. stability.

Key words: line, hybrid, oil, physicomechanical characteristics, geometric dimensions, shear, oxidative DOI: https://doi.org/10.31073/agrovisnyk202011-10

Sunflower is the most widespread oilseed crop in Ukraine. Its production is highly profitable, and edible oil is traditionally in great demand among the population [1]. The main direction of increasing the sunflower seeds production is the introduction of new high-yielding hybrids and intensive growing technologies into production [2-4].

In Ukraine, institutions of the National Academy of Agrarian Sciences of Ukraine work in the direction of sunflower selection. Annually in the state variety testing in Ukraine there are several dozen varieties and hybrids of sunflower, more than 10 new ones are included in the Register of Plant Varieties of Ukraine.

Now sunflower breeding is aimed not only at creating high-yielding seeds of new lines and different ripeness groups hybrids, with increased productivity, oil content, which is distinguished by resistance to aging, high adaptive ability to growing conditions and have genetically determined resistance to new common races of downy mildew, but also to replace the fatty acid composition of the oil [1-4].

Over the past 4 years, 33 sunflower hybrids of various ripeness groups have been created in Ukraine, with a potential yield of up to $5 \mathrm{t} / \mathrm{ha}$, seed oil content of at least $50 \%$, which are distinguished by their resistance to maturation, high adaptive ability to growing conditions and have genetically determined resistance to new common races downy mildew. As a result of breeding improvement, new sunflower hybrids have been created with different types of oil and basic fatty acid content, which significantly expands the scope of the crop. For the first time in Ukraine, sunflower hybrids of the selection of the V.Ya. Yuryev NAAN with a high content of palmitic acid (22-29\%) in oil, namely: Corporal Cursor, Truvor, Rubicon, Elitnyansky. There are new hybrids of oleic type like Zvezdopad, Maximus, Site, Raut, Oreol (the content of oleic acid in oil is 78 92\%) provide yield in production conditions at the level of 2.6-2.7 t/ha.

Now a significant part of marketable sunflower crops in Ukraine is occupied by foreign hybrids. However, in terms of productivity, domestic hybrids are not concede foreign ones, and therefore can be competitive. It should be noted that in new breeding lines and hybrids, not only physicochemical, but also physicomechanical and technological properties are partially changed, which have a direct impact on the conditions for processing oil seeds [5-7]. Therefore, the enterprises of the fat and oil industry have an urgent need to have data about physical and chemical parameters of seeds and oils of modern domestic sunflower hybrids for use in their economic activities, to control technological processes and the quality of oilseeds and fat products. This determines the relevance of this work, which is aimed at studying the seeds and oil of sunflower of the new line X526B (oleic type) of domestic selection. 
Purpose and main objectives of the study. The purpose of the research is to establish the physicochemical parameters and technological properties of sunflower seeds and oil of the new line X526B (oleic type) of domestic selection. To achieve this goal, it is necessary to solve the following tasks like to study the physicochemical characteristics, geometric dimensions and the process of seed shear; to investigate the physicochemical parameters, fatty acid composition and oxidative stability of the oil obtained from the seeds of a new line of oleic-type sunflower of domestic breeding.

Materials and research methods. For the research, we used sunflower seeds of a new line X526B (olein type), which were obtained from the V.Ya. Yuryeva NAAN.

Determination of moisture was performed according to DSTU ISO 665: 2008 "Oilseeds. Determination of moisture and volatile matter content (ISO 665: 2000, IDT) ". Determination of impurities - according to GOST ISO 658: 2006 "Oilseeds. Method for determination of impurity content (ISO 658: 2002, IDT) "or GOST 1085488" Oil seeds. Methods for determination of weed, oil and specially taken into account impurities ". Determination of oil content in seeds was performed according to DSTU ISO 659: 2007 "Oil seeds. Determination of oil content (control method) (ISO 659: 1998, IDT) ", DSTU 7096: 2009" Oil seeds. Determination of Oil Content by Accelerated Solvent Extraction ". Determination of the volumetric weight of sunflower seeds - according to GOST 4694: 2006 "Sunflower. Oil raw materials. Technical conditions ". Determination of the weight of 1000 pieces of seeds - according to [8]. Determination of the mass fraction of the shell in seeds - according to GOST 10855-64 "Oil seeds. Methods for determination of husk content ". Determination of linear dimensions of seeds - according to [8]. The fatty acid composition of the oil was determined according to DSTU ISO 5508-2001 "Animal and vegetable fats and oils. Study by gas chromatography of methyl esters of fatty acids (ISO 5508: 1990, IDT) ". Sample preparation for the determination of fatty acid composition was carried out in accordance with DSTU ISO 5509-2002 "Animal and vegetable fats and oils. Preparation of fatty acid methyl esters (ISO 5509: 2000, IDT) ". The DSC Q20 was used to determine the shelf life of the oil. The determination of the induction period from the kinetic curve of the oxidation of oils was carried out as recommended in Setting Up a DSC Oxygen Induction Time Procedure.

The processing of research results was carried out using software packages Microsoft Excel.

Results of work. At the first stage of the work, the physicochemical parameters of sunflower seeds of the X526B line were established (Table 1).

\section{Physicochemical indicators of sunflower seeds X526B}

\begin{tabular}{|c|c|c|c|}
\hline Indicator name & $\begin{array}{c}\text { Requirements of DSTU } \\
\text { 4694: } 2006 \text { "Sunflower. } \\
\text { Oilseeds. Technical } \\
\text { conditions" }\end{array}$ & Actual value & Test method \\
\hline 1 & 2 & 3 & 4 \\
\hline $\begin{array}{l}\text { moisture, \% } \\
- \text { not less } \\
- \text { not more } \\
\end{array}$ & $\begin{array}{l}6,0 \\
8,0 \\
\end{array}$ & 6,4 & DSTU 4811 \\
\hline $\begin{array}{l}\text { Admixture of weeds, \% not } \\
\text { more }\end{array}$ & 3,0 & 0,1 & GOST 10854 \\
\hline Oil impurities, \% not more & 7,0 & 3,5 & GOST 10854 \\
\hline $\begin{array}{l}\text { Acid number of oil, мг } \mathrm{KOH} / \mathrm{g} \text {, } \\
\text { not more }\end{array}$ & 5,0 & 0,65 & GOST 10858 \\
\hline $\begin{array}{ccc}\text { Mass } & \text { fraction of oil, } \\
\text { calculated on dry matter, } \%\end{array}$ & $33-57$ & 46,3 & DSTU 7577 \\
\hline & ss fraction of fatty acids, $\%$ & total fatty acic & \\
\hline $\mathrm{C}_{16: 0}$ - palmitic & & 4,3 & \multirow{4}{*}{ GOST 30418} \\
\hline $\mathrm{C}_{18: 0}$ - stearic & & 2,6 & \\
\hline $\mathrm{C}_{18: 1}$ - oleic & & 91,2 & \\
\hline$\overline{\mathbf{C}}_{18: 2}$ - linoleic & & 1,9 & \\
\hline \multicolumn{4}{|c|}{ Content of organochlorine pesticides, $\mathrm{mg} / \mathrm{kg}$, no more } \\
\hline DDT & 0,125 & Less 0,004 & MBB 081/12-0243-05 \\
\hline $\mathrm{HCH}$ (gamma isomer) & 0,5 & Less 0,004 & \\
\hline Heptachlor & 0,125 & absence & \\
\hline \multicolumn{4}{|c|}{ Content of toxic elements and mycotoxins, $\mathrm{mg} / \mathrm{kg}$, no more } \\
\hline Lead & 1,0 & 0,092 & \multirow{2}{*}{ MBB 081/12-0243-05 } \\
\hline Cadmium & 0,4 & 0,20 & \\
\hline Aflatoxin B1 & 0,005 & Less 0,001 & MP 2273 \\
\hline Zearalenon & 1,0 & Less 0,04 & GOST 28001 \\
\hline
\end{tabular}


The physical-mechanical characteristics of oil seeds include the linear dimensions of the seeds (length, thickness, width) and bulk density. The linear dimensions of seeds are one of the most important features and can vary over a relatively wide range, therefore, it is necessary to make mass measurements of seeds.

The geometric dimensions determination of 500 pieces of sunflower seeds of the X526B line has been carried out according to the guidelines for research methods and technological control and accounting for production in the fat and oil industry. To obtain experimental variational series, the data obtained were processed using the methods of mathematical statistics in the Excel software package. Variational curves are plotted (Fig. 1-3)

Частота, \%
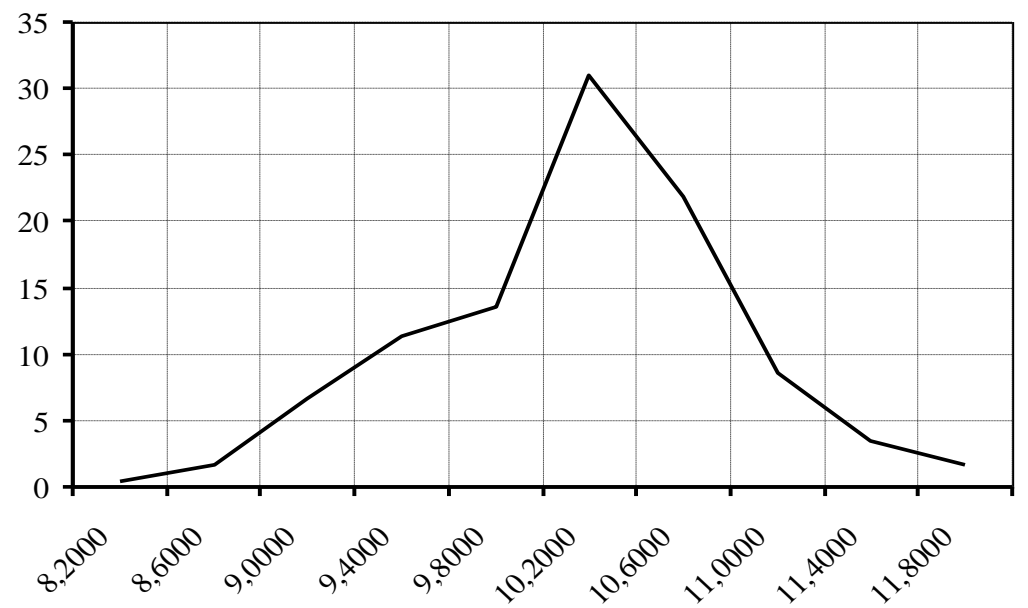

Довжина, мм

Fig. 1. Length distribution curve of sunflower seeds of olein type line X526 B

Частота, \%

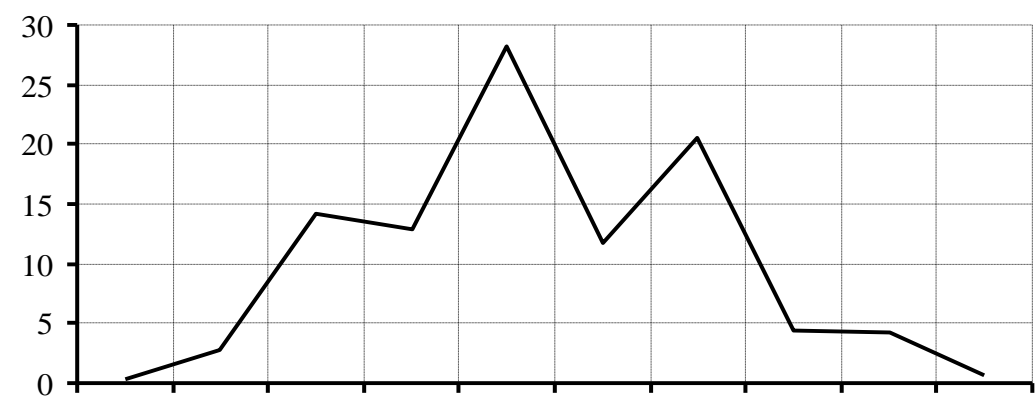

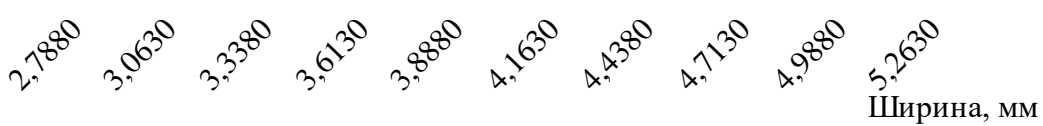

Fig. 2. Width distribution curve of seeds of olein-type sunflower of the line X526B.
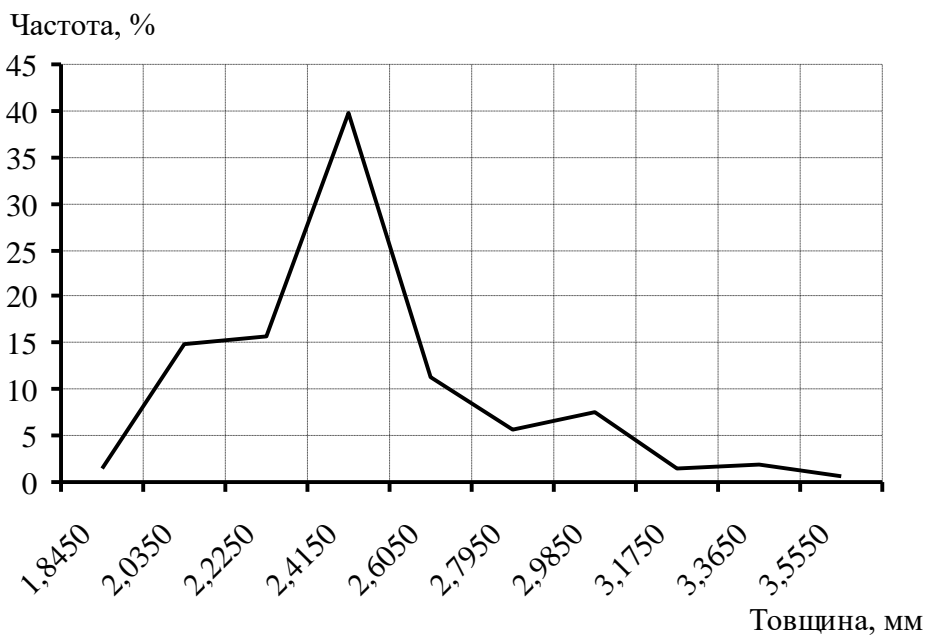

Fig. 3. Thickness curve distribution of seeds of olein-type sunflower of the line X526B 
Physicochemical characteristics of sunflower seeds are signs by which sieves are selected for the purpose of separating trash and sorting, calculating storage tanks and bunkers, transport devices, machines and for adjusting equipment operating modes. Fig. $1-3$ it is established: the frequency of appearance of X526B seeds of the same length and thickness is 31 and $40 \%$, respectively, which improves the cleaning of the seed mass from weeds and oil impurities before the sunflower seeds enter production. The width distribution curve of X526B sunflower seeds differs somewhat from the length and width distribution curves, since it has several frequency peaks $(28,23$ and $15 \%)$, which can complicate the process of selecting sieves for separating weeds.

The husk content of this line of sunflower seeds is $24 \%$, which coincides with this characteristic $(25-30 \%)$ previously used in the production of seeds.

The next stage of research was the determination of the quantitative and qualitative indicators of the process of dehulling the seeds of this sunflower line. The new line of sunflower seeds of the oleic type X526B, obtained through selection, has an increased content of oleic acid in the triglycerides of the oil, but at the same time the physicomechanical characteristics of the seeds, in particular the width (Fig. 2), are somehow different from the classical seeds, which may further affect conducting the process of separating the fruit shell from the kernel - crumbling..

Hulling of sunflower seeds is considered satisfactory if the rushanka contains a minimum amount of whole and half-cut seeds, chipped (crushed kernel), oily dust. It is impossible to obtain a husk-free kernel during the dehulling of sunflower seeds using the existing equipment in one pass [9]. The husk content in the kernel is recommended to be maintained at press plants - up to $10 \%$, at extraction plants - up to $14 \%$, for the production of confectionery - up to 1\% [9]. Statistical data in Ukraine indicate that for the extraction of oil, the kernel is supplied to enterprises with a husk content of $12-14 \%$ or more. In the case of a lower husk content, less accompanying substances (wax-like substances, free fatty acids, etc.) pass into the oil, and this improves the commercial and consumer properties of sunflower oil.

The research of sunflower seeds hulling was carried out in the field of centrifugal forces on a laboratory centrifugal "Semenorushka - 2 Ikhno" [10]. The hulling occurs due to a single blow directed along the long axis of the seeds, a blow with a blunt or sharp end. The hulling was performed at different speeds of the seed crusher rotor. The analysis of the obtained rushanka was performed according to the available methods. In this research, the seeds are brought to the hull with a moisture content of $\sim 7 \%$, as in most sunflower oil factories. The seed temperature before hulling is $+20 \stackrel{\circ}{ }$.

The results of the hulling are shown in table 2 and 3 , namely the fractional composition of the resulting product and the quantitative composition of fractions when sorting on sieves with round holes. The quantitative indicators of the hulling process were determined (Table 4).

2. The yield of sunflower seeds fraction when sorting on sieves at different speed of rotation of the rotor of the seed crusher

\begin{tabular}{|c|c|c|}
\hline \multirow{2}{*}{ Sieve } & \multicolumn{2}{|c|}{$\begin{array}{c}\text { Fraction content }(\%) \text { at the rotational speed of the seed crusher rotor } \\
\left(\mathrm{s}^{-1}\right):\end{array}$} \\
\cline { 2 - 3 } & 21,67 & 23,33 \\
\hline $\begin{array}{c}\text { Descending from a sieve with } \\
\text { holes } \\
\varnothing 4,5 \mathrm{~mm}\end{array}$ & 10,68 & 7,47 \\
\hline $\begin{array}{c}\text { Descending from a sieve with } \\
\text { holes } \\
\varnothing 3,5 \mathrm{~mm}\end{array}$ & 53,28 & 53,26 \\
\hline $\begin{array}{c}\text { Descending from a sieve with } \\
\text { holes } \\
\varnothing 3,0 \mathrm{~mm}\end{array}$ & 20,46 & 19,88 \\
\hline $\begin{array}{c}\text { Descending from a sieve with } \\
\text { holes } \\
\varnothing 1,0 \mathrm{~mm}\end{array}$ & 14,14 & 16,96 \\
\hline $\begin{array}{c}\text { Pass through a sieve with holes } \\
\varnothing 1,0 \mathrm{~mm}\end{array}$ & 1,44 & 2,43 \\
\hline Total & 100 & 100 \\
\hline
\end{tabular}


3. Fractional composition of sunflower seeds when sorting on sieves at different speed of rotation of the rotor of the seed crusher

\begin{tabular}{|c|c|c|c|}
\hline \multirow[t]{2}{*}{ Sieve } & \multirow[t]{2}{*}{ Fraction name } & \multicolumn{2}{|c|}{$\begin{array}{l}\text { Fraction content }(\%) \text { at the rotational speed of the } \\
\text { seed crusher rotor }\left(\mathrm{s}^{-1}\right) \text { : }\end{array}$} \\
\hline & & 21,67 & 23,33 \\
\hline 1 & 2 & 3 & 4 \\
\hline \multirow{3}{*}{$\begin{array}{l}\text { Descending from a sieve } \\
\text { with holes } \\
\emptyset, 4,5 \mathrm{~mm}\end{array}$} & $\begin{array}{l}\text { Kernel whole and } \\
\text { shredded }\end{array}$ & 0,19 & 0,19 \\
\hline & husk & 1,77 & 0,97 \\
\hline & $\begin{array}{l}\text { unrefined and whole } \\
\text { seeds }\end{array}$ & 8,72 & 6,31 \\
\hline \multirow{3}{*}{$\begin{array}{l}\text { Descending from a sieve } \\
\text { with holes } \\
\varnothing 3,5 \mathrm{~mm}\end{array}$} & $\begin{array}{l}\text { Kernel whole and } \\
\text { shredded }\end{array}$ & 21,62 & 21,16 \\
\hline & husk & 6,23 & 5,77 \\
\hline & $\begin{array}{l}\text { unrefined and whole } \\
\text { seeds }\end{array}$ & 25,43 & 26,33 \\
\hline \multirow{3}{*}{$\begin{array}{c}\text { Descending from a sieve } \\
\text { with holes } \\
\varnothing 3,0 \mathrm{~mm}\end{array}$} & $\begin{array}{l}\text { Kernel whole and } \\
\text { shredded }\end{array}$ & 15,65 & 14,73 \\
\hline & husk & 2,76 & 3,52 \\
\hline & $\begin{array}{l}\text { unrefined and whole } \\
\text { seeds }\end{array}$ & 2,05 & 1,63 \\
\hline \multirow{2}{*}{$\begin{array}{c}\text { Descending from a sieve } \\
\text { with holes } \\
\varnothing 1,0 \mathrm{~mm}\end{array}$} & crushed kernel & 8,25 & 10,33 \\
\hline & husk & 5,89 & 6,63 \\
\hline \multirow[t]{2}{*}{$\begin{array}{c}\text { Pass through a sieve } \\
\text { with holes } \\
\varnothing 1,0 \mathrm{~mm} \\
\end{array}$} & oil dust & 1,44 & 2,43 \\
\hline & Усього & 100 & 100 \\
\hline
\end{tabular}

\section{Quantitative indicators of the hulling process}

\begin{tabular}{|c|c|c|c|c|c|c|c|c|}
\hline \multirow[b]{2}{*}{ 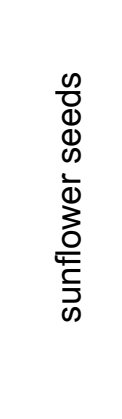 } & \multirow[b]{2}{*}{ 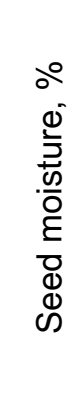 } & \multirow[b]{2}{*}{ 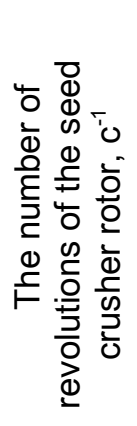 } & \multicolumn{6}{|c|}{ composition of rushanka, $\%$} \\
\hline & & & $\begin{array}{l}0 \\
\overline{0} \\
0 \\
\frac{0}{0} \\
\frac{0}{3}\end{array}$ & $\begin{array}{l}\frac{0}{\overline{0}} \\
\frac{0}{0} \\
\frac{0}{0} \\
\frac{1}{0}\end{array}$ & $\begin{array}{l}\frac{\infty}{0} \\
0 \\
0 \\
0 \\
0 \\
0 \\
0 \\
\frac{1}{3}\end{array}$ & 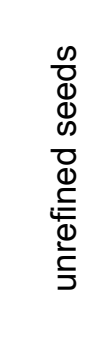 & 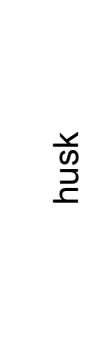 & $\begin{array}{l}\bar{y} \\
\frac{0}{0} \\
\overline{0}\end{array}$ \\
\hline \multirow{2}{*}{$\mathrm{X} 526 \mathrm{~B}$} & \multirow[b]{2}{*}{6,4} & 21,67 & 21,45 & 24,25 & 9,57 & 26,64 & 16,65 & 1,44 \\
\hline & & 23,33 & 15,4 & 31,09 & 2,69 & 31,5 & 16,89 & 2,43 \\
\hline
\end{tabular}

It was established that the amount of undershortening decreases with increasing of the hulling stages number, but at the same time, due to a decrease in the whole kernel, the amount of crushed kernel and cut increases. Under the conditions of the classical technology of sunflower seed hulling, the main influence on the quantitative and qualitative indices of hulling is the thickness of the air gap and the shell strength, while the technological parameters of the process (moisture of the seeds and the rotational seed crusher rotor speed) are minor importance.

After hulling by a single pressing method, there was obtained oleic-type sunflower oil. The dominant process that leads to oil deterioration is its thermal oxidation.

The study of oxidative stability was carried out under the following conditions: in isothermal mode, namely at $110^{\circ} \mathrm{C}$ temperature, the gaseous medium is air. The initial peroxide number for the oil obtained from the seeds of olein-type sunflower seeds of the new line X256B is $0.31 / 2 \mathrm{mg} \mathrm{O} \mathrm{mmol} / \mathrm{kg}$, which does not outweigh the indicator of the normative documentation.

An oxidation curve was obtained, which is a time dependence of the difference in heat fluxes measured in aluminum cuvettes with an oil sample and an empty one (Fig. 4). 
Тепловий потік, Вт/г

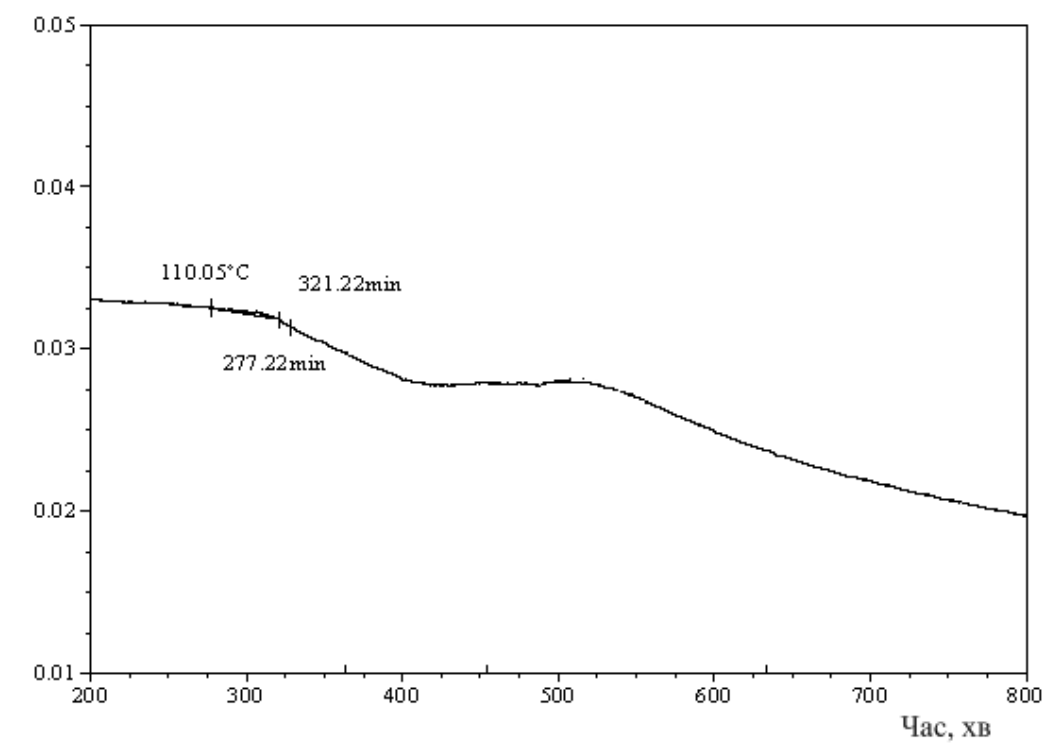

Fig.4. Oil oxidation curve of pressed filtered sunflower seeds of oleic type of the new line $X 526 B$ at a temperature of $+110^{\circ} \mathrm{C}$

The time value for the onset of rapid oxidation was found beyond the point corresponding to the onset of a steady drop in the heat flux. For an accurate assessment of the values, a special computer program for processing the parameters of the oxidation curve was used.

Basing on the data, we can reach that the induction period is the initial slow phase of the chemical reaction, after the exit from which a fast chain process begins, for sunflower seed oil of the oleic type of the new line X526B is 321 minutes. The obtained data are similar to the results for other viscooleic oils that exist in the database of the Ukrainian Research Institute of Oils and Fats of the NAAS.

\section{Conclusions}

The physicochemical characteristics of the seeds of the new line X526V have been established. The obtained indicators comply with the requirements of DSTU 4694: 2006 "Sunflower. Oilseeds. Technical conditions ". 2. The fatty acid composition oOf sunflower seed oil of oleic type of the new line X526B was determined. The oleic acid content in the triacylglycerides of the oil is $91.2 \%$, which confirms the oleic type of seeds. The geometrical dimensions of 500 pieces of sunflower seeds of the X526B line have been determined. The variation curves of seed size distribution were obtained. It was found that the frequency of appearance of $X 526 B$ seeds of the same length $(10.4 \mathrm{~mm})$ and thickness $(2.51 \mathrm{~mm})$ is 31 and $40 \%$, respectively. The width distribution curve $(3.47 \div 4.56 \mathrm{~mm})$ of sunflower seeds X526B has several frequency peaks (28, 23 and 15\%), which can complicate the process of selecting sieves for separating trash. The husk content of this sunflower seed line is at $24 \%$. The sunflower seeds hulling process of the new line X526B was studied and it was found that the amount of undershortening decreases with increasing in the number of hulling stages, but at the same time, due to decreasing in the whole kernel, the amount of crushed kernel and cut increases. With increasing in the number of seed crusher rotor rotations (from 21.67 to $23.33 \mathrm{~s}-1$ ), the content of the whole kernel (from 21.45 to $15.4 \%$ ) and seeds (from 957 to $2.69 \%$ ) decreases and the cut content increases (from 24.25 to $31.09 \%$ ), under-shedding (from 26.64 to $31.5 \%$ ) and oil dust (from 1.44 to $2.43 \%$ ). The husk content does not change. The oxidative stability (temperature $110^{\circ} \mathrm{C}$, gaseous medium - air) of seed oil of a new line of sunflower of oleic type of domestic selection Kh526V was determined. It was established that the induction period for this oil is 321 minutes, which proves that this oil is resistant to oxidation and can be used in cooking technologies at elevated temperatures.

\section{References}

1. Awatif, I., Arafat, Shaker. (2014). Quality Characteristics of High-Oleic Sunflower Oil Extracted from Some Hybrids Cultivated Under Egyptian Conditions. Journal of Food Technology Research, 1(2), 73-83. doi: 10.1515/helia-2014-0010

2. Akkaya, M., Çil, A., Çil, A., Yücel, H., Kola, O. (2018). The influence of sowing dates on the oil content and fatty acid composition of standard, mid-oleic and high-oleic types of sunflower (Helianthus annuus $L$.). Food Science and Technology, 39. doi: 10.1590/fst.20118

3. Alberio, C., Izquierdo, N., Galella, T., Zuil, S., Reid, R., Zambelli, A., Aguirrezábal, L. (2015). A new sunflower high oleic mutation confers stable oil grain fatty acid composition across environments. European Journal of Agronomy, 73. doi: 10.1016/j.eja.2015.10.003 
4. Alberio, C., Aguirrezábal, L., Izquierdo, N., Reid, R., Zuil, S., Zambelli, A. (2018). Effect of genetic background on the stability of sunflower fatty acid composition in different high oleic mutations. Journal of the Science of Food and Agriculture, 98. doi: 10.1002/jsfa.8924

5. Teslenko, S.A., Vryukalo, E.P., Perevalov, L.I. (2015). Osobennosti obrushivaniya gibridov podsolnechnika $v$ zamorozhennyam sostoyanii [The pecularities of dehulling sunflower hybrids' seeds in the frozen state]. The Bulletin of the National Technical University "Kharkiv Polytechnic Institute", 14, 7992. [in Russian].

6. Gürdil, G., Kabutey, A., Selvi, K., Hrabě, P., Herak, D., Fraňková, A. (2020). Investigation of Heating and Freezing Pretreatments on Mechanical, Chemical and Spectral Properties of Bulk Sunflower Seeds and Oil. Processes, 8, 1-20. doi: 10.3390/pr8040411

7. Aguirre, Marta R., Velasco, J., Ruiz-Méndez, M. Victoria. (2014). Characterization of sunflower oils obtained separately by pressing and subsequent solvent extraction from a new line of seeds rich in phytosterols and conventional seeds. Oleagineux Corps Gras Lipides, 21, 6. D605. doi: $10.1051 /$ ocl/2014033

8. Rzhehin, V.P., Sergeev, A.G. (Eds.) (1965). Rukovodstvo po metodam issledovaniya, tehnohimicheskomu kontrolyu i uchetu proizvodstva $v$ maslozhirovoy promyishlennosti [Guide to research methods, technological control and accounting of production in the oil and fat industry]. Leningrad: VNIIZh, 2. [in Russian].

9. Teslenko, S.A., Netreba, A.A., Vryukalo, E.P., Sadovnichiy, G.V., Perevalov, L.I. (2014). Vliyanie usloviy obrushivaniya vyisokomaslichnogo podsolnechnika na perehod voskov v maslo [Effect of high oilseed sunflower crushing conditions on the transition of waxes to oil]. Eastern-European journal of enterprise technologies, 1(10), 41-47. [in Russian].

10. Ihno, M.P. Patent. no. 17430 Ukraine, MPK $(1997,10)$ B02B 3/00, B02B 3/02. Nasinnerushka-2 Ihno [lkhnos grain husker-2]; Applicant and Patent Attorney Kharkov State Polytechnic University; no. u95042099; stated 27.04.95; posted by 31.10 97. p. 8. [in Russian]. 